\title{
Redescoberta de Hymenachne pernambucensis (Poaceae: Paspaleae), espécie presumivelmente extinta no Estado de São Paulo, Brasil
}

\author{
Rodrigo Sampaio Rodrigues ${ }^{1,2}$ e Tarciso de Sousa Filgueiras ${ }^{1}$
}

Recebido: 20.02.2012; aceito: 18.04.2013

\begin{abstract}
Rediscovery of Hymenachne pernambucensis (Poaceae: Paspaleae), a presumably extinct species in São Paulo State, Brazil). Recent analysis of herbarium collections of Hymenachne pernambucensis revealed that the species was erroneously classified as "presumably extinct" in São Paulo State. It is suggested that the conservation status of this taxon should be reevaluated in order to reflect the contemporary knowledge about the conservation status of the species.
\end{abstract}

Key words: conservation, grasses, Panicum pernambucense, red list

RESUMO - (Redescoberta de Hymenachne pernambucensis (Poaceae: Paspaleae), espécie presumivelmente extinta no Estado de São Paulo, Brasil). A recente análise de espécimes de Hymenachne pernambucensis em coleções de herbários revelou que a espécie foi erroneamente classificada como presumivelmente extinta no Estado de São Paulo. Sugere-se que o status de conservação deste táxon seja reavaliado de forma a refletir o atual conhecimento sobre a conservação da espécie. Palavras-chave: conservação, gramíneas, lista vermelha, Panicum pernambucense

\section{Introdução}

O primeiro volume da "Flora Fanerogâmica do Estado de São Paulo" é, até a presente data, o mais completo tratamento da flora de gramíneas do Estado. $\mathrm{Na}$ obra são descritos e ilustrados 104 gêneros e 475 espécies (Longhi-Wagner et al. 2001). Com a ampliação dos estudos florísticos e a informatização de coleções em todo o país, o número de táxons de Poaceae reconhecidos para a flora paulista tem sido constantemente revisto. Atualmente registram-se 120 gêneros e 500 espécies de Poaceae para a Flora de São Paulo (Longhi-Wagner et al. 2011).

Com a disponibilidade de dados sobre as espécies ocorrentes no Estado, um grande grupo de pesquisadores empenhou-se na sistematização de dados sobre o status conservacionista dessas espécies, o que resultou na publicação do Livro Vermelho das Espécies Ameaçadas da Flora do Estado de São Paulo (Mamede et al. 2007). Constam desta obra os nomes de 100 espécies de gramíneas classificadas com algum grau de ameaça.

Trabalhos posteriores evidenciaram a necessidade de revisão do status conservacionista de várias espécies. Filgueiras \& Shirasuna (2009) apresentam a redescoberta de cinco espécies classificadas como presumivelmente extintas (EX) no Estado, reencontradas durante levantamentos florísticos do projeto Rodoanel Mário Covas e em coletas na Serra da Bocaina, São José do Barreiro.

Semelhantemente, apresenta-se aqui mais uma espécie de gramínea, até o momento considerada como presumivelmente extinta da flora paulista, cujo status de conservação necessita ser revisado.

\section{Material e métodos}

Os espécimes analisados neste trabalho foram localizados durante visitas a vários herbários do Estado de São Paulo (IAC, SP, UEC) e ao herbário do Jardim Botânico do Rio de Janeiro (RB). Alguns foram obtidos como empréstimo e outros constam dos bancos de dados de coleções informatizadas com qualificador de identificação, i.e., identificadas por especialista, disponíveis para consulta pública no domínio INCT- Herbário Virtual da Flora e dos Fungos (http://inct.splink.org.br/).

1. Núcleo de Pesquisa Curadoria do Herbário, Instituto de Botânica, Caixa Postal 68041, 04301-902 São Paulo, SP, Brasil

2. Autor para correspondência: rosaro_3588@yahoo.com.br 


\section{Resultados e Discussão}

Hymenachne pernambucensis (Spreng.) Zuloaga é endêmica da América do Sul. No Brasil ocorre em áreas de Cerrado, Caatinga e Mata Atlântica, preferencialmente em bordas de rios, campos baixos e úmidos, ou ambientes sujeitos à inundação.

Na Flora do Estado de São Paulo, apenas dois espécimes são referidos por Zuloaga et al. (2001), ainda sob o nome do agora basiônimo Panicum pernambucense Spreng., ambos coletados na década de 1930. Este fato certamente contribuiu para a classificação da espécie como presumivelmente extinta por Mamede et al. (2007).

A tabela 1 apresenta vários espécimes coletados no Estado desde 1960, data a partir da qual, segundo os critérios utilizados por Mamede et al. (2007), a espécie não poderá mais ser classificada como presumivelmente extinta.

Os resultados disponíveis refletem a deficiência amostral dessa espécie que está representada por poucos espécimes nos herbários paulistas. Alternativamente, os dados também sugerem que se trata de espécie naturalmente escassa na natureza, pelo menos no Estado de São Paulo. Estudos posteriores poderão averiguar as duas possibilidades.

Diante dessas informações, sugere-se aqui a revisão da categoria de conservação dessa espécie, retirando-a da listagem de espécies presumivelmente extintas no Estado de São Paulo, e enquadrando-a em outra categoria que melhor

Tabela 1. Lista de espécimes de Hymenachne pernambucensis coletados a partir de 1960 no Estado de São Paulo, Brasil.

Table 1. List of Hymenachne pernambucensis specimens collected from 1960 onward in São Paulo State, Brazil.

\begin{tabular}{|c|c|c|c|}
\hline Local de coleta & Coletor e data de coleta & Ambiente & Herbário \\
\hline Rio Cotia, Cotia & $\begin{array}{l}\text { R.B. Torres et al. } 1005 \\
\text { 2-XII-2009 }\end{array}$ & Mata Ciliar & ESA, IAC, ICN \\
\hline Santa Rita do Passa Quatro & $\begin{array}{l}\text { A.D. Faria } 97 / 31 \\
\text { 13-I-1997 }\end{array}$ & Mata Ciliar & UEC \\
\hline Praia Azul, Americana & $\begin{array}{l}\text { A. Gentry } 49265 \\
\text { 6-I-1985 }\end{array}$ & - & $\mathrm{RB}$ \\
\hline Res. Biol. Mogi-Guaçu,Mogi-Guaçu & $\begin{array}{l}\text { H. Leitão-Filho et al. } 12279 \\
\text { 6-II-1981 }\end{array}$ & Mata Ciliar & UEC \\
\hline
\end{tabular}

represente o atual nível de conhecimento sobre seu status conservacionista.

Com base nos novos registros de ocorrência da espécie para o Estado de São Paulo, e confrontando-os com os critérios de classificação adotados por Mamede et al. (2007), sugere-se a inclusão da espécie sob a categoria preocupação menor (LC), visto que o táxon passa a atender somente a um critério (critério 9) dentre os 11 utilizados por esses autores.

Morfologicamente, H. pernambucensis caracteriza-se por apresentar ciclo perene, hábito cespitoso, ereto, com 0,7-2 m comprimento, bainhas glabras e lâminas glabras com base atenuada a subcordada, não amplexicaules, e margens escabrosas. A sinflorescência é composta por vários ramos unilaterais contraídos ou subcontraídos, densifloros.

Ilustrações desse táxon aparecem em Zuloaga et al. (1994), Zuloaga et al. (2001); imagens em Rodrigues (2013).

\section{Agradecimentos}

Aos colegas do Núcleo de Pesquisa Curadoria do Herbário SP, aos curadores dos herbários citados; e ao CNPq, pela bolsa de Mestrado concedida ao primeiro Autor.

\section{Literatura citada}

Filgueiras, T.S. \& Shirasuna, T. 2009. Redescoberta de espécies presumivelmente extintas de Poaceae da Flora de São Paulo, Brasil. Hoehnea 36: 507-509.

Longhi-Wagner, H.M., Bittrich, V., Wanderley, M.G.L. \& Shepherd, G.J. 2001. Poaceae. In: M.G.L. Wanderley, G.J. Shepherd \& A.M. Giulietti (coords.). Flora Fanerogâmica do Estado de São Paulo. Fapesp \& Hucitec, São Paulo. 
Longhi-Wagner, H.M., Valls, J.F.M., Oliveira, R.C., Zanin, A., Guglieri, A., Oliveira, R.P., Clark, L.G., Canto-Dorrow, T.S., Boldrini, I., Filgueiras, T. \& Londoño, X. 2011. Poaceae In: M.G.L. Wanderley, G.J. Shepherd, S.E. Martins, T.E.M.D. Estrada, R.P. Romanini, I. Koch, J.R. Pirani, T.S. Melhem, A.M.G. Harley, L.S. Kinoshita, M.A.G. Magenta, H.M.L. Wagner, F. Barros, L.G. Lohmann, M.C.E. Amaral, I. Cordeiro, S. Aragaki, R.S. Bianchini \& G.L. Esteves (coords.). Checklist das Spermatophyta do Estado de São Paulo, Brasil. Biota Neotropica 11: 342-354.

Mamede, M.C.H., Souza, V.C., Prado, J., Barros, F., Wanderley, M.G.L. \& Rando, J.G. (orgs.) 2007. Livro vermelho das espécies vegetais ameaçadas do Estado de São Paulo. Instituto de Botânica, São Paulo.
Rodrigues, R.S. 2013. A tribo Paniceae s.l. (Poaceae: Panicoideae) na Reserva Biológica de Mogi-Guaçu, SP, Brasil. Dissertação de Mestrado, Instituto de Botânica, São Paulo.

Zuloaga, F.O., Morrone, O., Rúgulo de Agrasar, Z.E., Anton, A.M., Arriaga, M.O. \& Cialdella, A.M. 1994. Gramineae V - Panicoideae-Paniceae, Acroceras StapfPanicum L. In: R. Spichiger \& L. Ramella (eds.). Flora del Paraguay. Conservatoire et Jardin Botaniques de la Ville de Genève \& Missouri Botanical Garden, Geneva $\&$ Saint Louis.

Zuloaga, F.O., Guglieri, A. \& Longhi-Wagner, H.M. 2001. Panicum. In: H.M. Longhi-Wagner, V. Bittrich, M.G.L. Wanderley \& G.J. Shepherd (eds.). Flora Fanerogâmica do Estado de São Paulo. Fapesp \& Hucitec, São Paulo, v.1, pp. 168-190. 